\title{
Sero-prevalence and factors associated with Toxoplasma gondii infection among pregnant women attending antenatal care in Mwanza, Tanzania
}

Berno Mwambe ${ }^{1 \dagger}$, Stephen E Mshana ${ }^{2 \dagger}$, Benson R Kidenya ${ }^{3^{*}+}$, Anthony N Massinde ${ }^{1}$, Humphrey D Mazigo ${ }^{4}$, Denna Michael ${ }^{5}$, Charles Majinge ${ }^{1}$ and Uwe Groß ${ }^{6}$

\begin{abstract}
Background: Serological screening of pregnant women for Toxoplasma gondii-specific antibodies is not practiced as an antenatal care in Tanzania; and there is a limited data about sero-prevalence of $T$. gondii infection in developing countries. We therefore conducted this study to determine the sero-prevalence and factors associated with T. gondii infection among pregnant women attending antenatal care clinics in Mwanza, Tanzania.

Methods: Between $1^{\text {st }}$ November 2012 and $31^{\text {st }}$ May 2013 a total of 350 pregnant women attending antenatal care clinics in Mwanza were enrolled and screened for IgG and IgM antibodies against $T$. gondii using the ELISA technique.

Results: Of 350 pregnant women, 108 (30.9\%) were sero-positive for T. gondii-specific antibodies. The risk of contracting T. gondii infection increases by $7 \%$ with each yearly increase in a woman's age $(\mathrm{OR}=1.07,95 \% \mathrm{Cl}$ : $1.02-1.11, p=0.002$ ). The sero-positivity rate of $T$. gondii-specific antibodies was higher among pregnant women from the urban than those from rural communities (41.5\% versus $22.0 \%)$; $[\mathrm{OR}=2.2,95 \% \mathrm{Cl}$; $1.4-3.7$, $\mathrm{p}=0.001$ ]. Likewise employed/business women were more likely to get $T$. gondii infection than peasants (40.0\% versus $25.9 \%)[\mathrm{OR}=1.9,95 \% \mathrm{Cl}: 1.2-3.0, \mathrm{p}=0.006]$.

Conclusions: Sero-prevalence of T. gondii-specific antibodies is high among pregnant women in Mwanza with a significant proportion of women at risk of contracting primary T. gondii infections. Screening of T. gondii infections during antenatal care should be considered in Tanzania as the main strategy to minimize congenital toxoplasmosis.
\end{abstract}

\section{Background}

Primary infections with $T$. gondii acquired during pregnancy are usually asymptomatic for the pregnant woman but can lead to serious neonatal complications [1]. Toxoplasmosis in pregnancy has been associated with miscarriage, hydrocephalus, cerebral calcification and chorioretinitis in the newborn [2]. Primary infection with T. gondii during the third trimester of pregnancy carries

\footnotetext{
* Correspondence: benkidenya@yahoo.com

${ }^{\dagger}$ Equal contributors

${ }^{3}$ Department of Biochemistry and Molecular Biology, Catholic University of Health and Allied Sciences, Box 1464, Mwanza, Tanzania

Full list of author information is available at the end of the article
}

a higher risk of congenital transmission than if it is acquired during the first trimester [3,4]. Generally, it is estimated that about one third of the world's population is infected with $T$. gondii $[5,6]$. In developed countries, congenital toxoplasmosis affects $0.01 \%-0.1 \%$ of infants [5]. In a study done in Dar es Salaam, Tanzania a sero-prevalence of $35 \%$ was reported in pregnant women in 1995 [7]. Since then there has been no follow-up study done and no intervention programme implemented. Antenatal serological screening of $T$. gondii infection based on IgG and IgM detection is the mainstay in monitoring the risk for congenital toxoplasmosis. Maternal-fetal intervention for toxoplasmosis can be achieved through the use of 
drugs such as spiramycine which prevents congenital infection by more than 60\% [5]. In Tanzania, there is no screening program during antenatal care for pregnant women. Therefore, this study aimed at determining the seroprevalence of $T$. gondii infection and its associated factors to provide basic information that could be used to justify the introduction of an antenatal screening programme in Tanzania.

\section{Methods}

An analytical cross-sectional health facility based study was conducted from $1^{\text {st }}$ November 2012 to $31^{\text {st }}$ May 2013 and was approved by Bugando Medical Centre/ Catholic University of Health and Allied Sciences ethics review committee. The study was conducted in Mwanza, in the three highly populated public antenatal care clinics as representative sites (Igombe Health Centre, Sekou-Toure

Table 1 Distribution of $T$. gondii sero-prevalence along with demographic characteristics among pregnant women, Mwanza, 2013

\begin{tabular}{|c|c|c|c|}
\hline \multirow[t]{3}{*}{ Patients characteristic } & \multicolumn{2}{|c|}{ T. gondii seroprevalence $(\mathrm{N}=350)$} & \multirow[t]{3}{*}{ Total } \\
\hline & Positive & Negative & \\
\hline & n (\%) & n (\%) & \\
\hline \multicolumn{4}{|l|}{ Age $(Y r)$} \\
\hline $15-24$ & $38(21.8)$ & $136(78.2)$ & 174 \\
\hline $25-34$ & $61(40.1)$ & $91(59.9)$ & 152 \\
\hline $35-44$ & $10(41.7)$ & $14(58.3)$ & 24 \\
\hline \multicolumn{4}{|l|}{ Residence } \\
\hline Urban & $68(41.5)$ & $96(58.5)$ & 164 \\
\hline Rural & $41(22.0)$ & $145(78.0)$ & 186 \\
\hline \multicolumn{4}{|l|}{ Occupation } \\
\hline Business & $37(37.8)$ & $61(62.2)$ & 98 \\
\hline Peasant & $57(25.9)$ & $163(74.1)$ & 220 \\
\hline Employed & $15(46.9)$ & $17(53.1)$ & 32 \\
\hline \multicolumn{4}{|l|}{ Education } \\
\hline Illiterate & $7(33.3)$ & $14(66.7)$ & 21 \\
\hline Primary & $66(27.2)$ & $177(72.8)$ & 243 \\
\hline Secondary and above & $36(41.9)$ & $50(58.1)$ & 86 \\
\hline \multicolumn{4}{|l|}{ Marital status } \\
\hline Married & $89(30.3)$ & $205(69.7)$ & 294 \\
\hline Unmarried & $20(35.7)$ & $36(64.3)$ & 56 \\
\hline \multicolumn{4}{|l|}{ Gravidity } \\
\hline Primigravid & $33(29.5)$ & $79(70.5)$ & 112 \\
\hline Multigravid & $61(32.5)$ & $127(67.5)$ & 188 \\
\hline Grandmultigravid & $15(30.0)$ & $35(70.0)$ & 50 \\
\hline \multicolumn{4}{|l|}{ Trimester } \\
\hline 1st Trimester & $4(26.7)$ & $11(73.3)$ & 15 \\
\hline 2nd Trimester & $50(33.3)$ & $100(66.7)$ & 150 \\
\hline 3rd Trimester & 55 (29.7) & 130 (70.3) & 185 \\
\hline
\end{tabular}

Regional Hospital and UMATI clinic). Igombe Health Centre is located in Ilemela district about 20 kilometers from Mwanza city centre, Igombe was considered as a rural area in this study. Sekou-Toure Regional Hospital and UMATI clinic are located in Mwanza city centre and were considered as urban areas. Mwanza is one of the largest cities of Tanzania and the capital of the Lake Victoria region. The staple foods for people living in Mwanza are maize, rice, fish, beef and chicken. The meat is usually cooked but may be eaten undercooked especially when taken in bars (Nyama Choma).

All pregnant women attended these clinics with gestational age between 8-42 weeks were serially enrolled until the sample size was reached. The sample size was estimated using the Kish Lisle formula for a cross-sectional study; a prevalence (p) of 35\% from the study in Dar es Salaam was used to calculate the sample size [7], resulting in a minimum sample size of 350 pregnant women.

\section{Sample collection procedure and laboratory work}

About $4 \mathrm{~mL}$ of venous blood was collected aseptically from each of the 350 pregnant women, of these 180 were from Igombe and 170 from UMATI and SekouToure. All specimens were transported to the Bugando Medical Centre where serum was separated from the whole blood by centrifugation at 3,000 rpm for 5 minutes. Separated serum was numbered and kept at $-80^{\circ} \mathrm{C}$ until transportation to Germany for further analysis at the National Consulting Laboratory of Toxoplasma. Sera were tested for anti-T. gondii antibodies using ELISA test kits (VIDAS Toxo-IgG-II-ELFA and Toxo-IgM-ELFA for anti- $T$. gondii-specific IgG and IgM antibodies respectively (bioMérieux GmbH, Nürtingen, Germany). The

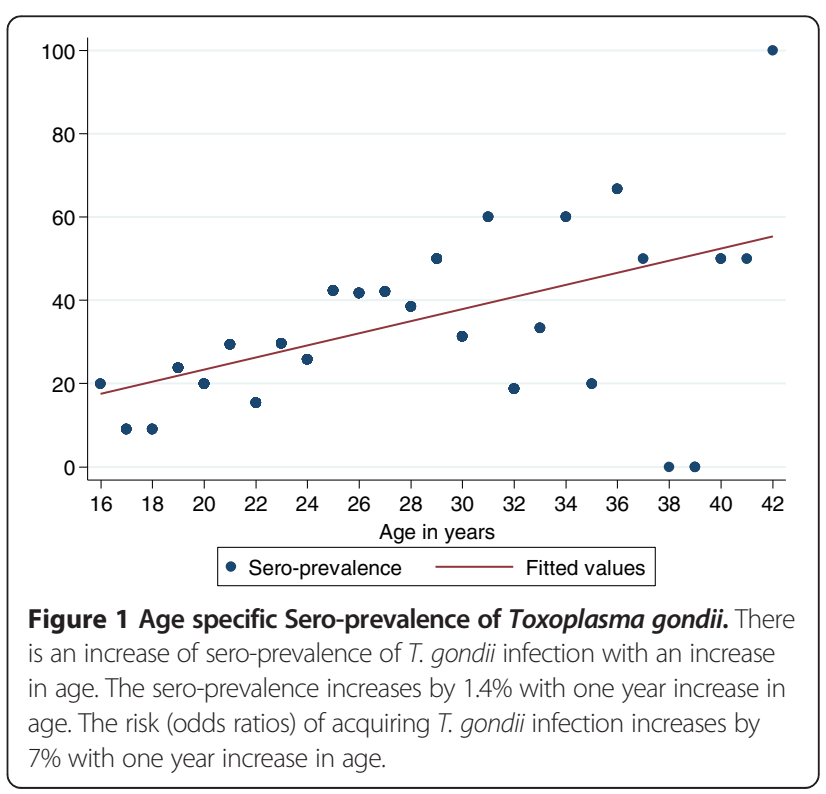


cut-off values for detection of IgG were as follows: IgG levels $<4 \mathrm{IU} / \mathrm{mL}$ were negative; IgG levels $4-<8 \mathrm{IU} / \mathrm{mL}$ were borderline and $\operatorname{IgG}$ levels $\geq 8 \mathrm{IU} / \mathrm{mL}$ were positive. The cut-off values for detection of IgM were as follows: IgM index value of $<0.55$ was negative; IgM index value of $0.55-<0.65$ was borderline and IgM index value of $\geq 0.65$ was positive. Demographic data such as age, residence, occupation, marital status, education, and relevant clinical information such as gravidity and trimester were collected using a pre-tested standardized data collection tool.

\section{Data management and analysis}

Data were entered into a computer using Microsoft Office Excel 2007 according to codes given, and analyzed using the STATA version 12 (College Station, Texas, USA). Categorical variables were summarized as proportions and were analyzed using the Pearson's Chi-square test to observe the differences among the various groups.
Continuous variables were summarized as mean \pm standard deviation. Univariate analysis and multivariate logistic regression models were fitted to determine factors associated with $T$. gondii infection. These factors were age, residence, occupation, education level, gravidity, eating of undercooked meat, drinking unsafe water and contact with cats. We used a backward-stepwise selection model to select factors with a p-value of less than 0.2 to be fitted into the multivariate logistic regression analysis. Odds ratios (OR) and their and 95\% confidence interval [95\% CI] were noted. Factors with the p-value of less than 0.05 on multivariate logistic regression analysis were considered to have a statistically significant association with T. gondii infection.

\section{Results}

A total of 350 pregnant women were enrolled during the study period with the mean age of $25.3 \pm 5.4$ years with

Table 2 Factors associated with $T$. gondii infection among pregnant women $(\mathbf{N}=350)$ in $M$ wanza

\begin{tabular}{|c|c|c|c|c|c|c|}
\hline \multirow[t]{2}{*}{ Patient's characteristic } & \multicolumn{2}{|c|}{ Toxoplasma sero-prevalence } & \multicolumn{2}{|c|}{ Univariate } & \multicolumn{2}{|c|}{ Multivariate } \\
\hline & $\begin{array}{c}\text { Positive } \\
\text { n (\%) }\end{array}$ & $\begin{array}{c}\text { Negative } \\
\text { n (\%) }\end{array}$ & OR $[95 \% \mathrm{Cl}]$ & p-value & OR $[95 \% \mathrm{Cl}]$ & $\mathrm{p}$-value \\
\hline \multicolumn{7}{|l|}{ Age (years) } \\
\hline $15-24$ & $38(21.8)$ & $136(78.2)$ & 1 & & 1 & \\
\hline $25-34$ & $61(40.1)$ & $91(59.9)$ & $2.4[1.5-3.9]$ & $<0.001$ & $2.2[1.4-3.7]$ & 0.001 \\
\hline $35-44$ & $10(41.7)$ & $14(58.3$ & $2.6[1.1-6.2]$ & 0.038 & $2.3[0.9-5.7]$ & 0.070 \\
\hline \multicolumn{7}{|l|}{ Residence } \\
\hline Rural & $41(22.0)$ & $145(78.0)$ & 1 & & 1 & \\
\hline Urban & $68(41.5)$ & $96(58.5)$ & $2.5[1.6-4.0]$ & $<0.001$ & $2.2[1.4-3.7]$ & 0.001 \\
\hline \multicolumn{7}{|l|}{ Occupation } \\
\hline Peasant & $57(25.9)$ & $163(74.1)$ & 1 & & & \\
\hline Employed/Business & $52(40.0)$ & $78(60.0)$ & $1.9[1.2-3.0]$ & 0.006 & - & - \\
\hline \multicolumn{7}{|l|}{ Education } \\
\hline Illiterate & $7(33.3)$ & $14(66.7$ & 1 & & & \\
\hline Primary & $66(27.2)$ & $177(72.8)$ & $0.7[0.3-1.9]$ & 0.545 & - & - \\
\hline Secondary/above & $36(41.9)$ & $50(58.1)$ & $1.4[0.5-3.9]$ & 0.476 & - & - \\
\hline \multicolumn{7}{|l|}{ Unsafe water } \\
\hline Yes & $62(28.1)$ & $159(71.9)$ & 1 & & 1 & \\
\hline No & $47(36.4)$ & $82(63.6)$ & $1.5[0.9-2.3]$ & 0.103 & $1.2[0.7-1.9]$ & 0.541 \\
\hline \multicolumn{7}{|l|}{ Gravidity } \\
\hline Primigravid & $33(29.5)$ & $79(70.5)$ & 1 & & & \\
\hline Multigravid & $61(32.5)$ & $127(67.5)$ & $1.1[0.7-1.9]$ & 0.590 & - & - \\
\hline Grandmultigravid & $15(30.0)$ & $35(70.0)$ & $1.0[0.5-2.1]$ & 0.945 & - & - \\
\hline \multicolumn{7}{|l|}{ Undercooked meat } \\
\hline Yes & $48(28.4)$ & $121(71.6)$ & 1 & & & \\
\hline No & $61(33.7)$ & $120(66.2)$ & $1.3[0.8-2.0]$ & 0.285 & - & - \\
\hline \multicolumn{7}{|l|}{ Contacts with Cat } \\
\hline No & 64 (32.6) & $132(67.4)$ & 1 & & & \\
\hline Yes & $45(29.2)$ & $109(70.8)$ & $0.9[0.5-1.3]$ & 0.491 & - & - \\
\hline
\end{tabular}


majority of women 174/350 (49.7\%) aged between 15-24 years. Most of the women were from a rural residence $186 / 350$ (53.1\%), peasants $220 / 350$ (62.9\%), married 294/ 350 (84.0\%), multigravid $188 / 350(53.7 \%)$ and on third trimester $185 / 350$ (52.9\%). The majority of women $243 /$ 350 (69.4\%) had primary education, with 86/350 (24.6\%) attaining a higher level of education (Table 1). Of the 350 pregnant women studied, 108 (30.9\%) were positive for anti-T. gondii-specific IgG antibodies, indicating past infection (Table 1). None had positive IgM results. The risk of contracting $T$. gondii infection increases by $7 \%$ with each yearly increase in a woman's age $(\mathrm{OR}=1.07$, 95\% CI: 1.02 - 1.11, $\mathrm{p}=0.002)$. The sero-prevalence increases by $1.4 \%$ with one year increase in age (Figure 1).

The sero-prevalence of $T$. gondii-specific IgG antibodies was higher in pregnant women residing in urban $(41.5 \%)$ than those in rural areas $(22.0 \%)$ [OR $=2.2,95 \%$ CI: 1.4 - 3.7, $\mathrm{p}=0.001$ ] (Table 2). A total of 220/350 (62.9\%) of the pregnant women were peasants, of these, 25.9\% (57/220) tested positive for T. gondii-specific antibodies. On univariate analysis there was a significant difference in Toxoplasma sero-positivity among individuals with different occupations; employed/business pregnant women had a higher sero-positivity rate of $T$. gondii-specific antibodies than peasants (40.0\% versus $25.9 \%$ ) (OR=1.9, 95\% CI: $1.2-3.0, p=0.006)$. The factor occupation of pregnant women was not subjected into multivariate analysis because it had a co-linearity relation with residence; as most of the peasants were living in rural areas.

\section{Discussion}

The sero-prevalence of $T$. gondii infection in this study was lower than that reported in Dar es Salaam, Tanzania two decades ago in which more than $35 \%$ of the pregnant women had evidence of $T$. gondii infections $[7,8]$. The difference could partly be explained by the geographical variation; Dar es Salaam is hotter than Mwanza and hotter weather has been found to favour sporulation of oocysts; secondly the difference could be due to the diagnostic methods, a study in Dar es Salaam used an immunosorbent agglutination assay while in the current study a highly specific ELISA method was used. However, the variation of sero-prevalence within a given country is not a new phenomenon; in USA the seroprevalence was found to vary from $17.5 \%$ in the west to $20.5 \%$ and $29.2 \%$ in the south-midwest and north-east, respectively [9]. Also the sero-prevalence in this study was low compared to studies in Brazil [10], Saudi Arabia [11], Morocco [12] and Sudan [13]. This may be accounted for by differences in climatic conditions, as reported before, where higher sero-prevalence is associated with hotter and wetter areas, which is favourable for sporulation of oocysts compared to less humid areas [14,15].
An increase in sero-positivity of anti- $T$. gondii antibodies was observed with increasing age in this study, which is consistent with other studies $[6,16]$. The observed risk increase per year might be considered high and may reflect higher infection risks at early adolescence. In this study, business women and employed pregnant women had higher infection rates with $T$. gondii than peasants, in contrary to other studies [6,17]. This may partly be explained by the economic status of the pregnant women in which more employed and business women, who have a high income compared to peasants; also tend to live in towns and can afford to eat poultry and pork which have been found to be a major source for T. gondii transmission $[17,18]$. This observation is further supported by the fact that, in this study, as it was observed in China [19]; residents from urban areas were more infected with $T$. gondii than those from rural areas.

Contaminated fruits and eating undercooked meat has been reported as a potential source of $T$. gondii infection [18,20-22]. Drinking contaminated water is another source of $T$. gondii infection [23,24]. A study done in Zaria, Nigeria documented a high sero-prevalence rate among pregnant women who drunk water from the well [25], this was not the case in the recent study done in Mexico [26] and in the present study. Contact with cat litter may pose another risk for T. gondii infection. However, in this study no significant association between $T$. gondii infection and a history of cat contact was found. The findings are consistent with studies done in Palestine [15], Turkey [21] and Nigeria [25]. Nevertheless, studies from Taiwan [27] and Ethiopia [6] showed a significant association between contact with cats and sero-prevalence of T. gondii. However, the risk of contracting T. gondii infection is not just the mere contact with cats but the way the cats' litter is handled.

\section{Conclusions}

Sero-prevalence of $T$. gondii-specific antibodies is high among pregnant women in Mwanza with a significant proportion of women at risk of contracting $T$. gondii infections. Advanced woman's age, urban residence and being an employed or a business woman were the independent risk factors associated with the presence of $T$. gondii infections. Screening of $T$. gondii infections during antenatal care should be considered in Tanzania as the main strategy to prevent and minimize congenital toxoplasmosis.

\footnotetext{
Competing interests

The authors declare that they have no competing interests.
}

\section{Authors' contributions}

BM, SEM, CM and UG participated in the design of the work. BM and AM participated in the collection of specimens and clinical data. UG analyzed the sample. BM, BRK, HDM, DM and SEM analyzed and interpreted the data. SEM and BRK wrote the first draft of the manuscript which was approved by all authors. All authors read and approved the final version of this manuscript. 


\section{Acknowledgements}

The authors would like to acknowledge the technical support provided by Benard Okamo and the Institute of Medical Microbiology Goettingen. We thank all staff in UMATI, Sekou-Toure and Igombe antenatal clinics for their technical support.

\section{Author details}

${ }^{1}$ Department of Obstetrics and Gynaecology, Catholic University of Health and Allied Sciences, Box 1464, Mwanza, Tanzania. ${ }^{2}$ Department of Microbiology/Immunology, Catholic University of Health and Allied Sciences, Box 1464, Mwanza, Tanzania. ${ }^{3}$ Department of Biochemistry and Molecular Biology, Catholic University of Health and Allied Sciences, Box 1464, Mwanza, Tanzania. ${ }^{4}$ Department of Parasitology, Catholic University of Health and Allied Sciences, Box 1464, Mwanza, Tanzania. ${ }^{5}$ Mwanza Research Centre National Institute of Medical Research Mwanza, Mwanza, Tanzania. Institute of Medical Microbiology and German Consulting Laboratory for Toxoplasma, Göttingen University Medical Center, Göttingen, Germany.

Received: 18 June 2013 Accepted: 2 August 2013

Published: 6 August 2013

\section{References}

1. Linguissi L: Seroprevalence of toxoplasmosis and rubella in pregnant women attending antenatal private clinic at Ouagadougou, Burkina Faso. Asian Pac J Trop Med 2012, 5(10):810-813.

2. Flatt A, Shetty N: Seroprevalence and risk factors for toxoplasmosis among antenatal women in London: a re-examination of risk in an ethnically diverse population. Eur J Public Health 2013, 23(4):648-52

3. Al-Hamdani M, Mahdi N: Toxoplasmosis among women with habitual abortion. EMHJ 1997, 3:310-315.

4. Dunn DWM, Peyron F, Petersen E, Peckham C, Gilbert R: Mother-to-child transmission of toxoplasmosis: risk estimates for clinical counseling. Lancet 1999, 353:1829-1833.

5. Montoya JG, Remington JS: Management of Toxoplasma gondii infection during pregnancy. Clin Infect Dis 2008, 47:554-566.

6. Zemene E, Yewhalaw D, Abera S, Belay T, Samuel A, Zeynudin A: Seroprevalence of Toxoplasma gondii and associated risk factors among pregnant women in Jimma town, Southwestern Ethiopia. BMC Infect Dis 2012, 12:337.

7. Doehring E, Reiter-Owona I, Bauer O, Kaisi M, Hlobil H, Quade G, Hamudu NA, Seitz HM: Toxoplasma gondii antibodies in pregnant women and their newborns in Dar es Salaam, Tanzania. Am J Trop Med Hyg 1995, 52:546-548.

8. Gill HSML: Prevalence of Toxoplasma antibodies in pregnant African women in Tanzania. Afr J Med Sci 1982, 11((4):167-170.

9. Jones JL: Toxoplasma gondii Infection in the United States: Seroprevalence and Risk Factors. Am J Epidemiol 2001, 154(4):357-365.

10. Vaz RT-SV, Sumikawa E, Guimarães A: Serological prevalence of Toxoplasma gondii antibodies in pregnant women from southern Brazil. Parasitol Res 2010, 106:661-665

11. Mohammad HIAT, Balaha MH, Moghannum MS: Toxoplasmosis among the pregnant women attending a Saudi maternity hospital: seroprevalence and possible risk factors. Ann Trop Med Parasitol 2010, 104:493-504.

12. El Mansouri BRM, Sebti F, Amarir F, Laboudi M, Bchitou R, Hamad M, Lyagoubi M: Seroprevalence of toxoplasmosis in pregnant women in Rabat, Morocco. Bull Soc Pathol Exot 2007, 100:289-290.

13. Elnahas AGA, Elbashir MI, Eldien ES, Adam I: Toxoplasmosis in pregnant Sudanese women. Saudi Med J 2003, 24:868-870.

14. Kistiah KBA, Winiecka-Krusnell J, Karstaedt A, Frean J: Seroprevalence of Toxoplasma gondii infection in HIV-positive and HIV-negative subjects in Gauteng, South Africa. South Afr J Epidemiol Infect 2011, 26(4):225-228.

15. Nijem KA-AS: Seroprevalence and associated risk factors of toxoplasmosis in pregnant women in Hebron district, Palestine. East Mediterr Health $J$ 2009, 15:1279-1284.

16. Rosso F: Prevalence of infection with Toxoplasma gondii among pregnant women in Cali, Columbia, South America. Am J Trop Med Hyg 2008, 78:504-508

17. Ahmed HJMH, Yusuf MW, Ahmed SF, Huldt G: Human toxoplasmosis in Somalia. Prevalence of Toxoplasma antibodies in a village in the lower Scebelli region and in Mogadishu. Trans R Soc Trop Med Hyg 1988, 82(2):330-332.
18. Sroka JW-FA, Szymanska J, Dutkiewicz J, Zajac V, Zwolinski J: The occurrence of Toxoplasma gondii infection in people and animals from rural environment of Lublin region -estimate of potential role of water as a source of infection. Ann Agric Environ Med 2010, 17(1):125-132.

19. Hao Y: Difference of Toxoplasma gondii infection status between urban and rural childbearing age women visiting to hospitals in southwest region of Shandong Province. Zhongguo Xue Xi Chong Bing Fang Zhi Za Zhi 2013, 25(1):113-114.

20. Koskiniemi M, Lappalainen M, Hedman K: Toxoplasmosis needs evaluation. An overview and proposals. Am J Dis Child 1989, 143:724-728.

21. Ghoneim NSS, Hassanain N, Zeedan G, Soliman Y, Abdalhamed A Detection of genomic Toxoplasma gondii DNA and anti-Toxoplasma antibodies in high risk women and contact animals. Global Veterinaria 2009, 3:395-400

22. Alvarado-Esquivel C, Estrada-Martínez S, Liesenfeld O: Toxoplasma gondii infection in workers occupationally exposed to unwashed raw fruits and vegetables: a case control seroprevalence study. Parasit Vectors 2011, 16:4-235.

23. Ertug SOP, Tukmen M, Yuksel H: Seroprevalence and risk factors for Toxoplasma infection among pregnant women in Aydin province, Turkey. BMC Publ Health 2005, 5:66.

24. Bowie WRKA, Werker DH, Isaac-Renton JL, Bell A, Eng SB, Marion SA: Outbreak of toxoplasmosis associated with municipal drinking water. Lancet 1997, 350:173-177.

25. Ishaku BAI, Umoh J, Lawal I, Randawa A: Seroprevalence and risk factors for Toxoplasma gondii infection among antenatal women in Zaria, Nigeria. Res J Medicine \& Med Sc 2009, 4:483-488,

26. Alvarado-Esquivel C, Campillo-Ruiz F, Liesenfeld O: Seroepidemiology of infection with Toxoplasma gondii in migrant agricultural workers living in poverty in Durango, Mexico. Parasit Vectors 2013, 6(1):113.

27. Lin YL, Liao YS, Liao LR, Chen FN, Kuo HM, He S: Seroprevalence and sources of Toxoplasma infection among indigenous and immigrant pregnant women in Taiwan. Parasitol Res 2008, 103(1):67-74.

doi:10.1186/1756-3305-6-222

Cite this article as: Mwambe et al:: Sero-prevalence and factors associated with Toxoplasma gondii infection among pregnant women attending antenatal care in Mwanza, Tanzania. Parasites \& Vectors $20136: 222$

\section{Submit your next manuscript to BioMed Central and take full advantage of:}

- Convenient online submission

- Thorough peer review

- No space constraints or color figure charges

- Immediate publication on acceptance

- Inclusion in PubMed, CAS, Scopus and Google Scholar

- Research which is freely available for redistribution 